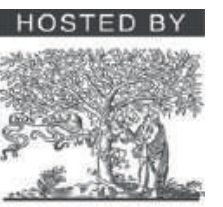

Case report

\title{
External jugular vein aneurysm in a young woman: An uncommon cause of neck mass
}

\author{
Hamit Serdar Başbuğ a,*, Macit Bitargil a ${ }^{\text {a }}$, Ahmet Karakurt ${ }^{b}$, Kanat Özışık ${ }^{a}$ \\ a Department of Cardiovascular Surgery, Kafkas University Faculty of Medicine, Kars, Turkey \\ b Department of Cardiology, Kafkas University Faculty of Medicine, Kars, Turkey
}

\section{A R T I C L E I N F O}

\section{Article history:}

Received 30 November 2015

Received in revised form 22 December 2015

Accepted 23 December 2015

Available online 10 March 2016

\section{Keywords:}

External jugular vein

Aneurysm

Neck

Mass

\begin{abstract}
A B S T R A C T
External jugular vein aneurysms are extremely rare pathologies compared to arterial ones. The patients often present with a painless mass in the neck that becomes visible while coughing and straining. Palpation of a soft and compressible swelling over the external jugular vein is a diagnostic hallmark. Doppler ultrasound examination is considered as the golden standard for the radiological diagnosis that allows a precise determination and confirmation of an aneurysm. Surgical excision is performed mostly for cosmetic concerns and symptomatic aneurysms. In this article, we present the clinical aspects, radiological and microscopic findings, diagnosis and surgical treatment of an external jugular vein aneurysm in a young female patient to emphasize the typical clinical presentation of this rare entity.

(c) 2016 The Society of Cardiovascular Academy. Production and hosting by Elsevier B.V. All rights reserved. This is an open access article under the CC BY-NC-ND license (http://creativecommons.org/licenses/by-nc-nd/4.0/).
\end{abstract}

\section{Introduction}

Venous aneurysms were initially described by Harris in 1928 after the presentation of an infant with a congenital venous cyst of the mediastinum. ${ }^{1}$ The terminology of a venous aneurysm was then suggested by Hilscher in 1995 to create a similarity to arterial aneurysms. ${ }^{2}$ In contrary to the arterial aneurysms, venous aneurysms are rarely seen. They can be presented in any veins throughout the body including thoracic, cervical, visceral and lower extremity veins. However, due to the lowpressure system of the superior vena cava, the venous aneurysms of the head and neck are rarely encountered than the deep veins of the abdomen and lower limbs. ${ }^{3}$ In this paper, diagnosis and the surgical treatment of an external jugular vein aneurysm in a young woman were reported.

\section{Case report}

A 19-year-old female was referred for a right neck mass that has been noticed for five years. The mass was non-tender, soft, compressible and bluish and located in the right supraclavicular area. It was clearly visible in rest, but becoming more prominent with Valsalva maneuver (Fig. 1). There was no pulsation or a murmur over the mass that could be heard. The mass has been growing gradually in time and had no association with breathing or swallowing. In her anamnesis, there was a

\footnotetext{
* Corresponding author at: Kafkas University Faculty of Medicine, Department of Cardiovascular Surgery, Kars, Turkey. Tel.: +90 505 2612372; fax: +90 4742251193. E-mail address: s_basbug@hotmail.com (H.S. Bașbuğ).

Peer review under responsibility of The Society of Cardiovascular Academy.
}

history of a lipoma excision in the right supraclavicular region eleven years ago when she was eight.

The initial diagnosis was a right jugular vein ectasia to explain the increase in size with Valsalva. A cystic lymphangioma extending into the mediastinum was also considered. Ultrasound (US) imaging revealed a fusiform venous structure measuring $2.5 \times 3.5 \times 1.5 \mathrm{~cm}$ on the right anterolateral neck with an existing flow by Doppler US. The mass was over the trace of the right external jugular vein and had no relation to the internal jugular vein. The flow pattern and the morphology of the right common carotid artery were normal. Magnetic resonance angiography imaging showed a round shaped lesion above the right clavicula with a high contrast uptake consistent to a vascular structure (Fig. 2).

Surgical treatment was planned after the diagnosis of a venous aneurysm and the anamnesis of gradual enlargement of the mass. The patient was operated electively with a simple excision of the mass (Fig. 3). It was found to be a right external jugular venous aneurysm consistent with the preoperative diagnosis and measurements (Fig. 4). The pathologic investigation with a microscope revealed an aneurysmatic dilatation of the vein with a focal thinning of smooth muscle wall consistent with phlebectasia. The patient was discharged the next day with no complication and scheduled for a routine follow-up.

\section{Discussion}

Venous aneurysms are uncommon causes of the cervical masses when compared to arterial ones. ${ }^{2}$ Aneurysms of the neck veins are extremely rare because of the low intravascular pressure in the superior vena cava system. ${ }^{4} \mathrm{~A}$ venous aneurysm can be either primary (congenital) or secondary (acquired). Congenital aneurysms are 


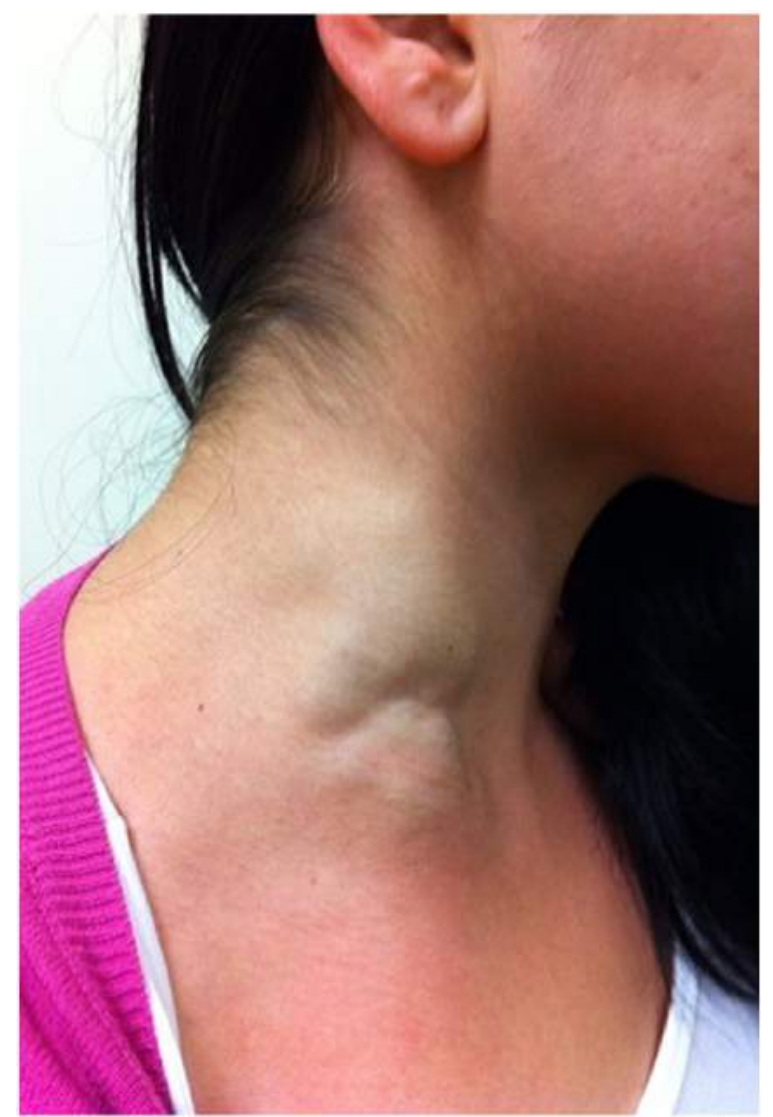

Fig. 1. External jugular vein aneurysm of a 19-year-old woman.

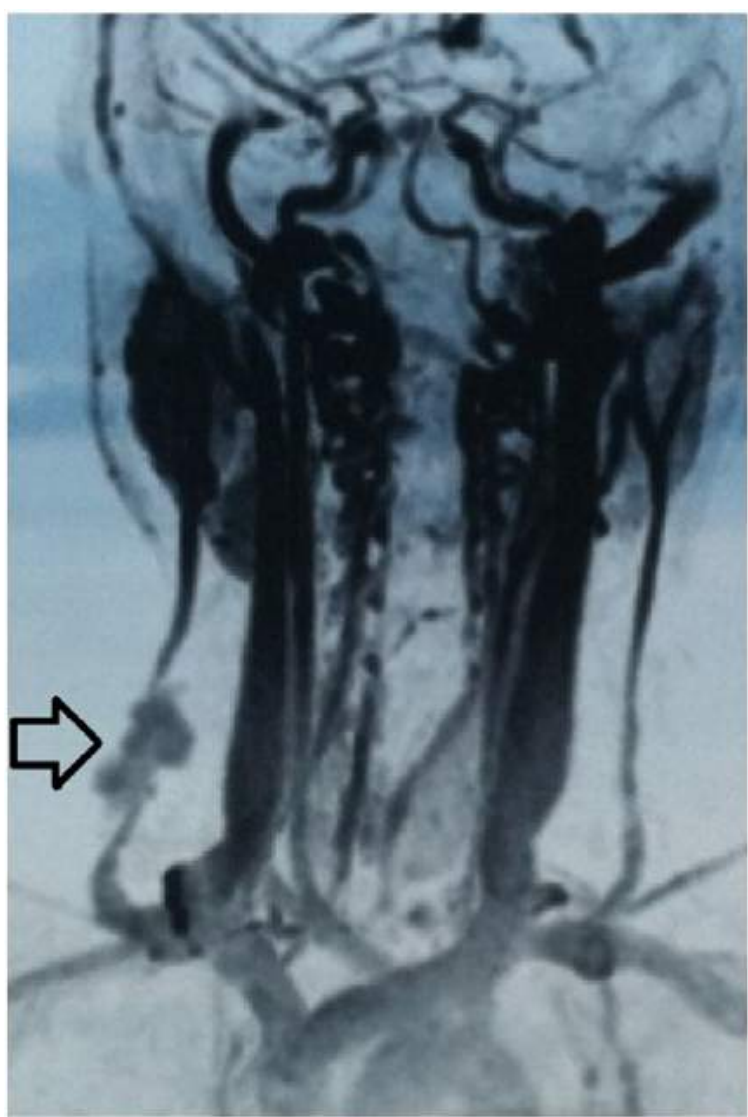

Fig. 2. Magnetic resonance angiography image reveals a venous aneurismatic dilatation on the right external jugular vein.

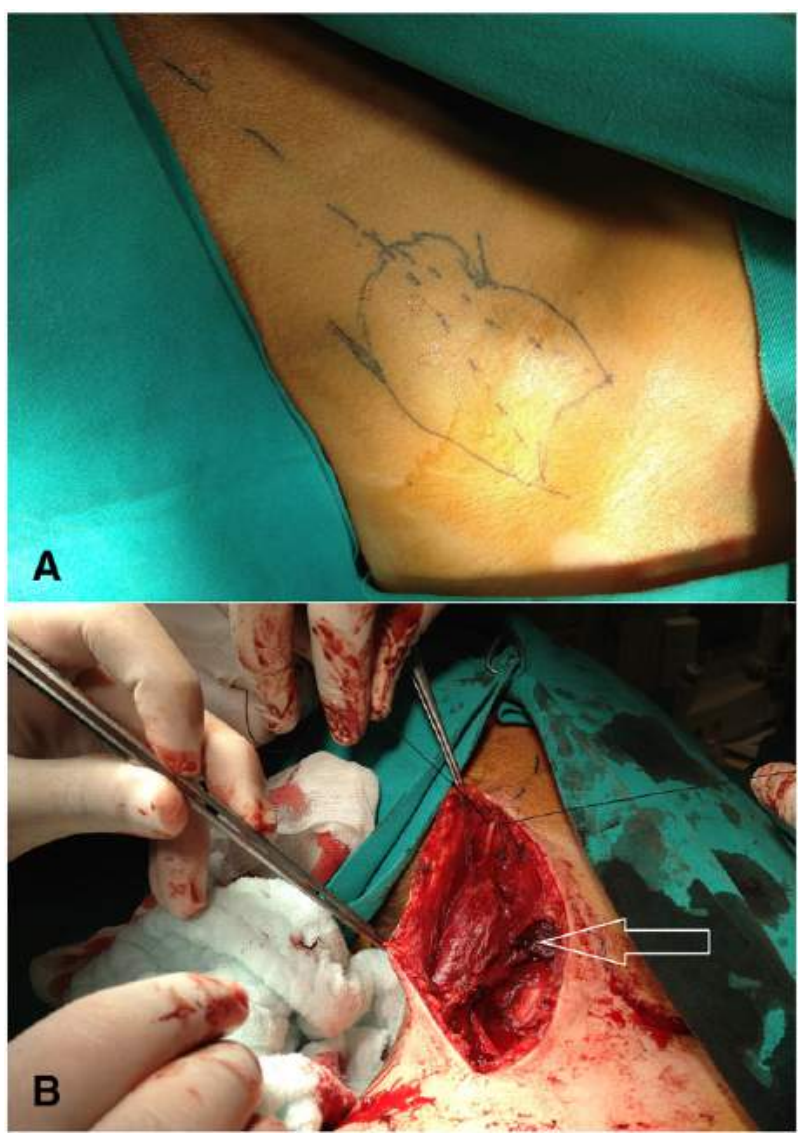

Fig. 3. A. Mapping before the surgical intervention. B. Exploration and delineation of the mass before excision.

considered as true aneurysms as they have an intact venous wall with a weakness of elastic fibers. ${ }^{2,5}$ Various etiological mechanisms have been proposed for the development of acquired venous aneurysms. These include trauma, chronic inflammation, degeneration, and increased pressure. $^{5}$

In the differential diagnosis of a cervical mass, cystic hygroma, cavernous hemangioma, a lymphocele, a laryngocele, an enterogenous cyst, thyroid swelling, lymphadenopathy, a thyroglossal cyst, a dermoid cyst and a branchial cleft cyst should be considered. ${ }^{4,5}$ Engorgement of the neck swelling during strain eliminates others than a laryngocele and jugular vein aneurysm. The absence of air inside the lesion on plain roentgenography further eliminates the laryngocele. ${ }^{4}$

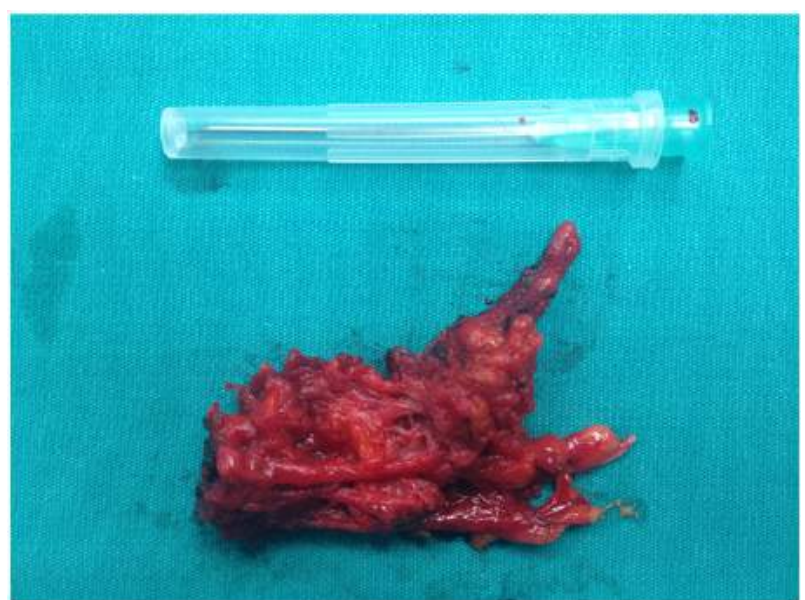

Fig. 4. Macroscopic aspect of the excised external jugular vein aneurysm. 
Diagnosis of jugular vein aneurysms can be achieved by color Doppler US imaging (with and without Valsalva), computed tomographic angiography, magnetic resonance angiography imaging, and venography. ${ }^{6}$

Histopathologic examination of the specimen may show a broad spectrum of findings varying from normal venous wall to those unique to phlebectasia. ${ }^{5}$ The term phlebectasia has been increasingly recognized in recent years indicating the venous dilatation without tortuosity. ${ }^{7}$ Phlebectasia is a condition including the thinning of the venous wall with the loss of smooth muscle cells and their replacement with a fibrous layer as well as the disruption of the elastic layer.,

Asymptomatic external jugular vein aneurysms can be monitored with regular follow-up. However, surgical excision should be considered for the cosmetic reasons or the presence of a painful aneurysm secondary to phlebitis or thrombosis. ${ }^{9}$ Surgical removal also eliminates the theoretical risk of aneurysmal rupture and pulmonary embolism. ${ }^{10} \mathrm{It}$ also allows surgeons to get the exact histopathological diagnosis. Saccular type of external jugular venous aneurysms can be safely treated by excision and ligation. Whereas, an exclusion and bypass may be needed in a fusiform aneurysm. ${ }^{9,10}$ The rarity of this type of venous aneurysms may be related to the asymptomatic nature of them or the tendency of reporting only surgical results. ${ }^{11}$

\section{Conflict of interest}

None declared.

\section{Consent}

Written informed consent was obtained from the patient for publication of this case report and accompanying images. A copy of the written consent is available for review by the Editor-in-Chief of this journal on request.

\section{References}

1. Harris RI. Congenital venous cyst of the mediastinum. Ann Surg 1928;88(5):953-957

2. Ekim H, Özen S. Primary venous aneurysm of the external jugular vein. EJM 2002;7: 24-25.

3. Regina G, Cardia G, Squeo MA, Lillo A, Latorre M, Odero A. Aneurysm of the internal jugular vein-a case report. Vasc Surg 1988;22(3):169-171.

4. Kirmani S, Rashid M, Ali I, Badar F. External jugular vein aneurysm: a rare cause of neck swelling. J Ultrasound Med 2011;30(8):1157-1158.

5. Al-Shaikhi A, Kay S, Laberge JM. External jugular venous aneurysm: an unusual cause of a neck mass in a young child. J Pediatr Surg 2003;38(10):1557-1559.

6. Karapolat S, Erkut B, Unlu Y. Multiple aneurysms of the left external jugular vein. Turk J Med Sci 2005;35(1):43-45.

7. Paleri V, Gopalakrishnan S. Jugular phlebectasia: theory of pathogenesis and review of literature. Int J Pediatr Otorhinolaryngol 2001;57(2):155-159.

8. Cadariu F, Avram J, Enache A, et al. External jugular vein aneurysm: case report. J Exp Med Surg Res 2010;17:271-274.

9. Ascher E, Salles-Cunha S, Hingorani A. Morbidity and mortality associated with internal jugular vein thromboses. Vasc Endovasc Surg 2005;39(4):335-339.

10. Mohanty D, Jain BK, Garg PK, Tandon A. External jugular vein aneurysm: case report. J Nat Sci Biol Med 2013;4(1):223-225.

11. Sander S, Elicevik E, Unal M, Vural O. Jugular phlebectasia in children: is it rare or ignored? J Pediatr Surg 1999;34(12):1829-1832. 